Tesis, 10(11), 2017, 91-100

\title{
El discurso del Amo en las cartas de amor de César Moro ${ }^{1}$ \\ The speech of the Owner in the letters of love of César Moro
}

\author{
Jhonny Jhoset Pacheco Quispe \\ Universidad Nacional Mayor de San Marcos \\ jhonnypachecoquispe@gmail.com
}

\section{Resumen}

Estudia una cartografía de tres temas que subyacen en la poesía de César Moro, específicamente, La tortuga ecuestre (1957) y Cartas a Antonio (1938-1939). En el primero, se analiza la «metáfora del amor» en la cual se establece la gestación del amor, y el discurso lírico amoroso de un amado, erómenos, hacia un amante, erastés. En el segundo, el concepto del «discurso del Amo», que muestra una jerarquización y subordinación de poder entre los actuantes, el Amo y el Esclavo, que genera diversas implicancias insertadas como eje de funcionamiento poético; a partir de ello, se menciona la idea de una gran carta literaria que quiso realizar el autor de Amour à mort, como se puede recoger e inferir en textos escritos durante el periodo mexicano (1938-1948). Finalmente, se analiza las Cartas a Antonio, sobre tópicos como la mimetización con la realidad, el pensamiento mítico, la destrucción del referente, etc.

Palabras claves: César Moro, poesía, amor, carta, Amo y Esclavo.

\begin{abstract}
He studies a cartography of three themes that underlie César Moro's poetry, specifically the Equestrian Turtle (1957) and Letters to Antonio (1938-1939). In the first, the "metaphor of Love" is analyzed in which the gestation of love is established, and the loving lyrical speech of a loved one, Erómenos, towards a lover, erastés. In the second, the concept of the "Discourse of the Master", which shows a hierarchy and subordination of power between the actuators, the master and the Slave, which generates various implications inserted as a axis of poetic functioning; From this, it is mentioned the idea of a great literary letter that wanted to make the author of Amour à mort, as can be collected and inferred in texts written during the Mexican period (1938-1948). Finally, it analyzes the Letters to Antonio, on topics such as the camouflage with the reality, the mythical thought, the destruction of the referent, etc.
\end{abstract}

Keywords: Cesar Moro, poetry, love, letter, Master and Slave. 


\section{El discurso del Amo en las cartas de amor de César Moro}

\section{Principiando por el recorrido de la metáfora pasional}

¿Quién ama a quién? fue una de las primeras preguntas que me formulé cuando acabé de leer, hace ya varios años, la poesía de César Moro. Me intrigó, de sobremanera, cuál era la relación de poder que se establecía entre los amantes, es decir, si existía una igualdad de correlación entre estos actuantes o había una actitud de sujeción y dominio entre ambos. En aquella cascada de amor devorador, de imágenes fulgurantes y de realidad trastocada, los versos no podían configurar una armonía vital, una síntesis en la unión amorosa y clamorosa de dos personas, sino, todo lo contrario, la violenta absorción del otro y la idealización extrema hasta arribar a lo obsceno. Por supuesto, aquella idea me demandaría algunos años de investigación, compilación de bibliografía, análisis de su producción poética, y adquisición de primeras ediciones donde comprobaba, de alguna u otra forma, dichas perspectivas.

No obstante, existía ante mi propuesta un aparato crítico que se había encargado de establecer una correspondencia amorosa repetida hasta el cansancio: en la poesía de César Moro existe el discurso de un amante hacia un amado, por ello, uno observa la violencia lírica y la deificación del otro. Desde los primeros acercamientos hechos por André Coyné hasta Julio Ortega, Elena Altuna, Claudia Salazar, Camilo Fernández, Américo Ferrari, entre otros, continuaron sustentando la misma posición enunciadora en la poesía moreana. El escollo exegético presentado no tenía el andamiaje analítico en ciernes, sino que se encontraba enraizado por una tradición.

Entre los años 2012 y 2014 me enfoqué en sustentar o refutar mi punto de vista que se encontraba a contracorriente de la opinión generalizada: ¿cuál era la relación de dominio entre los amantes? Al no encontrar mayor soporte que 
mi formulación propuesta, entonces, decidí estudiar la metáfora del amor, la creación del sentimiento amoroso que tanto ha caracterizado la lírica de César Moro. Uno de los libros que me encauzó por dicho tema fue el Seminario 8. La transferencia, de Jacques Lacan, en el que se diserta la génesis del amor mediante una acción milagrosa, lo real (2003, p. 64). Lo interesante de ello fue descubrir cómo se expresaba esta situación pasional a través de ciertos patrones de conductas manifestados entre el amante y el amado. De este modo, la teoría lacaniana me hizo discernir lo siguiente: el amor se gesta y se despliega no por el amante, como muchos consideran tal vez por la fuerza e intensidad que conlleva per se, sino por el amado, fuente de irradiación y objeto de veneración. ¿Por qué Lacan afirma lo siguiente? Tomando las referencias platónicas de El banquete, el amado, o también llamado erómenos, es la única persona que daría hasta su propia vida por salvaguardar la de su amante, erastés (2006, p. 20). Menciona Platón que en una guerra, un ejército de amados sería una tropa invencible si supieran que sus cohortes de amor están en peligro (pp. 18-19). Por esta disposición de funcionalidad, tuve que cotejar algunos textos de la tradición filosófica para tener una hipótesis estructurada antes de afirmar o contradecir la doxa de los intérpretes moreanos.

De este modo, revisé el diálogo platónico mencionado en el cual logré encontrar la teoría del amor. En sus páginas, el filósofo griego ejemplifica la potestad del amado sobre el amante, así como su actitud y deificación hacia este, al referirse al caso de Aquiles y Patroclo. Como se sabe, a la muerte de este último, la reacción de venganza del primero solo es comparable con el comportamiento de un amado (pp. 20-21); incluso, Platón menciona otras características que confirman de que Aquiles era el erómenos, por ello, su desaforada reacción (p. 20). Asimismo, me cultivé con una variedad de textos para entender fehacientemente esa idea de dominio y tránsito amoroso, verbigracia, el Menón, de Platón; la Ética a Nicómaco, de Aristóteles; el Elogio del amor, de Alain Badiou, La llama doble, de Octavio Paz, entre otros. Empero, aún no encontraba el punto de apoyo que me permitiría socavar un canon crítico ya anquilosado.

Cuando empezaba a desentramar los estudios hermenéuticos sobre la poesía de César Moro, por un azar objetivo hallé el artículo "El poeta y su bestiario", de André Coyné, a la edición española de La tortuga ecuestre y otros poemas en español (2002) realizada por Américo Ferrari. En dicho texto, por error o adrede, Coyné diserta sobre la direccionalidad enunciadora del amante y el amado en el sentimiento amoroso, donde el erastés invierte sus funciones con el erómenos y se comporta como este (p. 91). Es una idea rápida, sin mayor desarrollo ni reiteración de lo dicho, dado que luego continúa con su exordio sobre el amor del amante por el amado. Por momentos he pensado que fue un error de escritura o un lapsus genial; sin embargo, gracias a ello, un horizonte distinto comenzó a edificarse en mis mientes. 
Efectivamente, amparado en lo que mencionó el peruanista francés, observé que la poesía de Moro, específicamente en La tortuga ecuestre, Lettre d'amour, Cartas a Antonio y otros textos del periodo mexicano (1938-1948), dialogaba con la óptica disertada por Coyné. Así, inicié un análisis sobre el marco bibliográfico que durante años se había mantenido rígido respecto a la voz poética que canta a un amado. Producto de este escudriñamiento fue mi tesis de $\mathrm{Li}^{-}$ cenciatura intitulada La metáfora del amor en La tortuga ecuestre de César Moro (2014). Empero, mi búsqueda e interrogantes continuaron orbitando en torno a la obra completa del autor de Los anteojos de azufre.

\section{A la búsqueda del discurso del Amo}

A mediados del año pasado, con una investigación realizada y con las posibilidades de extender mi discurso de la metáfora del amor en el teatro Oeil de perdrix, o en otros libros en francés del autor de Pierre des Soleils, esta situación cambió cuando, como un coup de foudre, apareció ante mí una noticia esperada desde hace varios años: la aparición en 2015 de la Obra poética completa de César Moro por la Colección Archivos. Esta noticia no fue prevista, pues un año antes Ricardo Silva Santisteban había narrado en detalle la crónica de aquel naufragio editorial. A partir de este suceso, él se había comprometido en realizar dicha publicación en otra edición, misión que cumplió en 2016 cuando editó las Obras completas de César Moro en cinco tomos.

Al tener la totalidad de la producción moreana, se abrieron ante mí muchas posibilidades de análisis, por ejemplo, profundizar en un estudio pormenorizado de ciertos poemas desconocidos o manuscritos inéditos. Nuevamente orienté mis facultades hacia la empresa de la Tesis de Maestría con el fin de expiarme de ciertas dudas dejadas en mi estudio anterior. Así, retorné a la teoría psicoanalítica y revisé varios libros de Jacques Lacan, donde encontré un texto que me orientó sobre un mar de incertidumbres: el Seminario 17. El reverso del psicoanálisis.

En este territorio teórico deseaba obtener el discernimiento sobre la existencia de un dominio entre el amante y el amado, es decir, si había una funcionalidad más allá de la temática amorosa y si tenía relación con cuestiones ontológicas, metafísicas o de jerarquización de poder. Esto último fue lo que hallé con las implicancias en la gestación y metáfora del amor. Si en una Tesis me acerqué a la creación del amor, lo que buscaba ahora en la Tesis de Maestría era ceñirme al funcionamiento que mantenía dicho régimen amoroso; dicho de otra manera, ¿qué hace posible que el amor se sostenga? Así, hallé en el mencionado Seminario 17, de Jacques Lacan, el discurso del Amo, una toma de posición de dominio, alguien quien manda a otro, el Amo y el Esclavo. A partir de ello, extrapolé este mecanismo situado en el proceso psicoanalítico hacia la 
poesía de César Moro, con el que obtuve la siguiente afirmación: el discurso del Amo es un proceso de relaciones subordinantes entre dos actuantes, el Amo y el Esclavo, que cumple como eje de funcionamiento poético y que despliega una serie de implicancias: el Amo no sabe sobre su dominio; el Amo se ilusiona; el Esclavo sí sabe y es quien trabaja para posicionar al Amo, así como mantener la estructura de subordinación; el Amo está ciego ante su comunión con el objet petit $a$, puesto que no hay un fantasma que cubra esta correspondencia no concordante; y el Instinto de Muerte que causa zozobra en el sistema, dado que con el fenecimiento del Esclavo todo se aniquilaría y volvería a empezar, ya que con la muerte del Amo no se espera nada, ni un cambio.

Ante ello, me establecí nuevas metas en relación a este tópico con el objetivo de realizar una adecuada aplicación a la poesía de César Moro, especialmente, las Cartas a Antonio. En consecuencia, regresé a las lecturas de los griegos, verbigracia, el Menón, de Platón, en el que hallé la relación entre el Amo y el Esclavo, donde el segundo "trabaja" y "sabe" la verdad de su actividad para que el primero pueda vivir y gobernar sin mayores complicaciones sobre aquel. Estas coordenadas de dominio y poder me llevaron al Contrato social, de Rousseau, y a un texto inigualable por las consistencias semánticas y sociales que ha logrado desplegar por sus ideas, la Fenomenología del espiritu, de Hegel. En este libro se trata de manera explícita este tema, el cual le sirvió de base a Lacan para establecer su conceptualización del discurso del Amo. Con un lenguaje abstruso, Hegel delinea, de manera dialéctica, la interrelación entre el Amo y el Esclavo, creándose una sociedad en el que el primero es la piedra angular de todo lo construido. Esta dinámica, por supuesto, trasciende a niveles de la Historia. Con ello, aunque llevándolo a otro campo de acción, Lacan relaciona y organiza el discurso del Amo en conjunto con los afectos y las relaciones de poder.

Teniendo ciertos parámetros del mencionado discurso, principiamos que en la poesía de César Moro se expele dicha relación a través de las metáforas e imágenes incandescentes que enuncia el amado, erómenos, hacia el amante, erastés, no solo en textos como La tortuga ecuestre, "ANTONIO es Dios", Le château de grisou, Lettre d'amour, Amour à mort, sino también en las Cartas a Antonio, proyecto poético que estudiamos en nuestra Tesis de Maestría El discurso del Amo en las Cartas a Antonio de César Moro (2017).

\section{El gran proyecto de la carta literaria}

Varios investigadores moreanos han coincidido en apuntar que el poeta quiso realizar una gran carta, una sola epístola distinta y creativa e inigualable, como así lo han recogido André Coyné, Américo Ferrari, Julio Ortega y Ricardo Silva-Santisteban; por supuesto, dicho proyecto no encajaba dentro de las formas convencionales de la escritura, o el formato cotidiano de una circular. Prueba 
de ello se manifiesta en algunos poemas de La tortuga ecuestre, por ejemplo, "La vida escandalosa de César Moro"; las prosas poéticas Cartas a Antonio, que a modo de correspondencia, desarrolla un tránsito amoroso desde el deslumbramiento del amante y la aparición del amor hasta la melancolía y nostalgia por la pérdida del objeto de deseo, el erastés; el poema "ANTONIO es Dios", donde el tono apóstrofe comporta una correspondencia íntima; y Lettre d'amour, que por su formato y escritura hacen explícito el cometido moreano de la carta. A partir de este procedimiento escritural, el vate surrealista intenta desestabilizar una práctica pasiva y confidencial, como es el género epistolar, para convertirla en una praxis transgresora, en el cual lo íntimo aflora para perderse entre los límites de la poesía y el origen de lo circundante, la palabra.

De acuerdo a esta perspectiva, César Moro realizó esta transgresión de la norma literaria en su vasta obra. Así, en un escrito de Sebastián Salazar Bondy, "Moro, Ternura y Felicidad" (1958) publicada en La Prensa, nos menciona que el poeta surrealista utilizaba la prosa en los artículos con el fin de tocar temas sociales, económicos, o de índole político (p. 8), por ejemplo, "A propósito de la pintura en el Perú", texto donde el vate expresa su enérgico rechazo al arte exotista que no permite la gestación de una conciencia verdadera; mientras que en la carta, el bardo la usaba para tratar asuntos personales, trascendentes y amorosos (p. 8), como sucede en sus diferentes creaciones de índole epistolar. Esto último afirma la postura de los críticos moreanos acerca de la carta literaria en el que la escritura se sumerge en el amor descarnado, sin tabúes, terrenal. Dicha disyuntiva de la prosa de Moro nos posiciona en ese intersticio abismal, donde lo correcto y lo incorrecto se imbrican, en el que el amor y el aspecto social se hallan frente a frente unidos en un solo cordón umbilical: el lenguaje.

En cuanto a las Cartas a Antonio, estas tienen como fecha referencial los años de 1938-1939, lapso que se inserta dentro del «ciclo de Antonio» y que corresponde al «periodo mexicano» (1938-1948), etapa de esplendor expresada en las metáforas contradictorias, impactantes y de gran riqueza semántica poética. En estas tierras, al parecer, encontró el escritor peruano un mundo idealizado, ancestral, o como diría Yolanda Westphalen en su Tesis de Licenciatura, César Moro. La poética del ritual y la escritura mítica de la modernidad (1997), una ritualidad, en el que la máscara de la modernidad se posiciona sobre un pensamiento mítico. En su correspondencia, a cada momento, hay una exaltación de la naturaleza, una descripción titánica y deificadora del mismo mundo, así también del erastés que lo asemeja con un dios demoniaco. El erómenos se sitúa en medio de esta realidad sagrada como un ente profano que intenta mimetizarse con lo circundante sacralizado, pues la naturaleza ha sido la creadora de todo lo existente, incluso de "Antonio".

Ahora bien, en esta loa en favor del mundo natural, no debemos dejar de anotar la enunciación del amado hacia un amante. Aquí hay una prosa 
altamente lírica, donde existe una destrucción de la realidad para que el erastés logre posicionarse como un tótem, un axis mundi del orden, pues en el verdadero orbe, el objeto-causa de deseo ya no está. Este proceso principia con la epístola "I: Domingo: 23 de octubre [de 1939]", en el cual el amado enuncia la presencia del amante a la vez que muestra su subordinación en pleno éxtasis amoroso; empero, el emisor manifiesta su preocupación por la posible pérdida de su receptor: "Apenas te alejas y ya el cielo radioso se oscurece" (Moro, 2002, p. 432). Esto último se transfiere y manifiesta en la correspondencia "II: 25 de enero de 1939”, en el que existe una desesperación por la ausencia o posible desaparición del ser amado. Hay una desmesurada presencia sensorial de Antonio que fungirá de guía del poeta entre las tinieblas: "y tu voz me haga nacer y me devuelva al mundo de mí mismo que he perdido al encontrarte sin hallarte" (Moro, 1998, p. 125).

En la siguiente carta "III: 28 de febrero, medianoche", nos situamos en pleno deseo y estructuración del amante con la realidad: "Desearte es ver todos los árboles y el cielo, el agua y el aire en ti” (p. 136). Y si no se produce el amor, o ya no existiese la relación entre el erómenos y erastés, la muerte y la destrucción desatada está a flor de piel en las palabras del emisor: "¡Si yo no amara! Sería la guerra de cien años de mi vida" (p. 136); también, “¿quién puede consolarme del trance de la muerte y darme la certeza, la única que pido, de amarte exactamente a través de todas las transformaciones post mortem?” (p. 136). Recordemos que en la relación del Amo y el Esclavo, el Instinto de Muerte es una situación que está rondando y puede aparecer en cualquier circunstancia, ya que significa la emancipación de una vida hecha para trabajar, amar, y vivir en suplicios; es decir, la muerte implica una revolución vital, anímica y afectiva, pues la interrelación que los mantiene unidos se destruiría. Con ello, el amor dejaría de funcionar y la trascendencia no podría realizarse.

En la siguiente circular "IV: 18 de junio de 1939", el dominio y exacerbación es fulgurante y constante. El Esclavo, el amado, ya está alienado en la vida del amante, tanto que logra decir: "Tu historia es la historia del hombre", "Nada existe fuera de ti, solo el silencio y el espacio” (p. 137). En la alienación plena en la que está imbricado el amado, aún puede reconocer su dominio del amor como uno de los sentimientos más fuertes e invencibles ante cualquier embate: "tu rabia es menos fuerte que mi amor" (p. 137). Entonces, arribamos al mismo argumento que ya hemos sostenido en párrafos anteriores: el amor de un amado-Esclavo es infinito y esplendoroso, ya que ni siquiera la rabia y crueldad del amante-Amo lo puede igualar.

En el escrito "V: 25 de julio de 1939", la intensidad de los versos y el lenguaje descarnado se empiezan a prefigurar. Ya no hay censura, sino una apología exhibicionista a los órganos sexuales, dado que son los elementos progenitores de lo existente: "tu paso de centella por la avenida de los dioses donde termina 
la Vía Láctea que nace de tu pene” (p. 141). Antes al amante ya lo había descrito como un "demonio nocturno", un "caballo apocalíptico", rabioso, que trastoca el tiempo, la noche, los siglos. También, el amor del amado no tiene límites ni comparación: "No puedo resolverme a aceptar el hecho evidente, crudelísimo, de saberte distante... Nada es comparable a la sensación de mi ternura" (p. 141). Esta última cita que pertenece a la carta fechada con "VI: 10 de octubre de 1939” solo confirma el tono amoroso del erómenos, un fuego sin parangón que puede arriesgar hasta la vida misma.

Luego de la sexta circular, ya no tenemos más misivas. El proyecto de la gran carta se frustró. Como lo expresan los exégetas moreanos, el amor se acabó, por tanto, la gestación de esta correspondencia lírica y transgresora se volvió imposible. Lamentablemente, al quedarse en un proyecto fallido, no se logró realizar una forma poética novedosa y transgresora en el género epistolar, como sí sucedió en otras expresiones literarias y líricas comenzadas en la década del 20 y continuada en los años 30 en la literaria peruana.

Solo nos resta decir, luego de esta disertación, que aún existe mucho por investigar y que tanto la metáfora del amor como el discurso del Amo son tópicos que recorren no solo la poesía de César Moro, sino también su variada obra artística que falta descubrir, analizar y valorar.

\section{Notas}

1 Este artículo es una parte de mi Tesis de Maestría titulada El discurso del Amo en las Cartas a Antonio de César Moro.

\section{Referencias}

Aristóteles. (2001). Ética a Nicómaco. Madrid: Alianza Editorial.

Coyné, A. (2002). El poeta y su bestiario. En: César Moro. La tortuga ecuestre y otros poemas en español. Madrid: Biblioteca Nueva.

Hegel, G. W. F. (2006). Fenomenología del Espiritu. Traducción de Manuel J. Redondo. Valencia: Pre-Textos.

Lacan, J. (2003). El seminario 8. La transferencia. Buenos Aires: Paidós.

- (1998). Seminario 1. Los Escritos Técnicos de Freud. Buenos Aires: Paidós.

- (1997). El seminario 7. La ética del psicoanálisis. Buenos Aires: Paidós.

- (1996). El seminario 17. El reverso del psicoanálisis. Buenos Aires: Paidós.

Moro, C. (2002). Prestigio del amor. Selección, traducción y prólogo de Ricardo Silva-Santisteban. Colección El Manantial Oculto 11. Lima: Pontificia Universidad Católica del Perú. 
- (1998). Prestigio del amor. Selección, traducción y prólogo de Ricardo Silva-Santisteban. Obras esenciales 1. Ediciones del Rectorado. Lima: Pontificia Universidad Católica del Perú.

Platón. (2006). El banquete. Barcelona: Folio.

- (1999). Menón. Madrid: Biblioteca Nueva.

Salazar Bondy, S. (24 de junio de 1958). Moro, Ternura y Felicidad. En: La Prensa, p. 8.

Westphalen, Y. (1997). César Moro. La poética del ritual y la escritura mítica de la modernidad. Tesis para optar el Título de Licenciatura en Literatura. Universidad Nacional Mayor de San Marcos. Lima.

Rousseau, J. (2007). El contrato social. Madrid: Austral. 